\title{
Endoscopic ultrasound-guided gallbladder drainage by transjejunal lumen-apposing metal stent placement in a patient with mini-gastric bypass
}

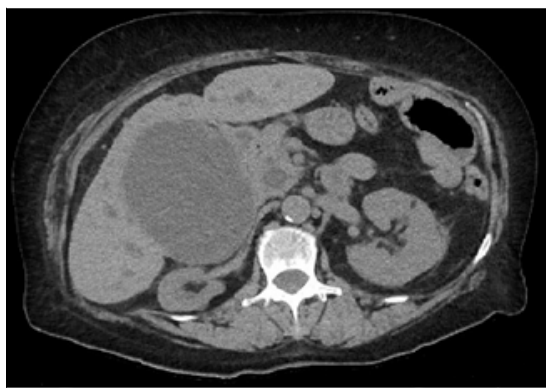

- Fig. 1 Computed tomography showing a distended gallbladder adherent to the jejunal loop.

Endoscopic ultrasound-guided gallbladder drainage (EUS-GBD) using lumen-apposing electrocautery-enhanced metal stent (EC-LAMS) is a safe and effective treatment option in patients with acute cholecystitis who are unfit for surgery [1]. We present the case of a 64-year-old woman who presented to the emergency department with a grade III cholecystitis [2] ( $>$ Fig. 1). The patient had dilated cardiomyopathy with an implanted cardioverter-defibrillator, decompensated type II diabetes, and had undergone mini-gastric bypass surgery for obesity control 10 years ago. She was deemed unfit for surgery at this time and endoscopic drainage was proposed [3] ( $\vee$ Video 1 ).

EUS revealed an over-distended gallbladder attached to the efferent loop of the gastrojejunal anastomosis. EUS-GBD was therefore performed by transmural placement of an EC-LAMS (Hot Axios, $10 \times 10 \mathrm{~mm}$; Boston Scientific, Marlborough, Massachusetts, USA) (> Fig.2), allowing the release of a significant amount of purulent bile from the gallbladder into the jejunal efferent loop ( $\vee$ Video 1). After the procedure, the patient's general status progressively improved (>Fig.3); however, 2 weeks after the procedure, fever persisted and a second endoscopic procedure was planned. Using a duodenoscope, the efferent limb was reached and the LAMS was still in

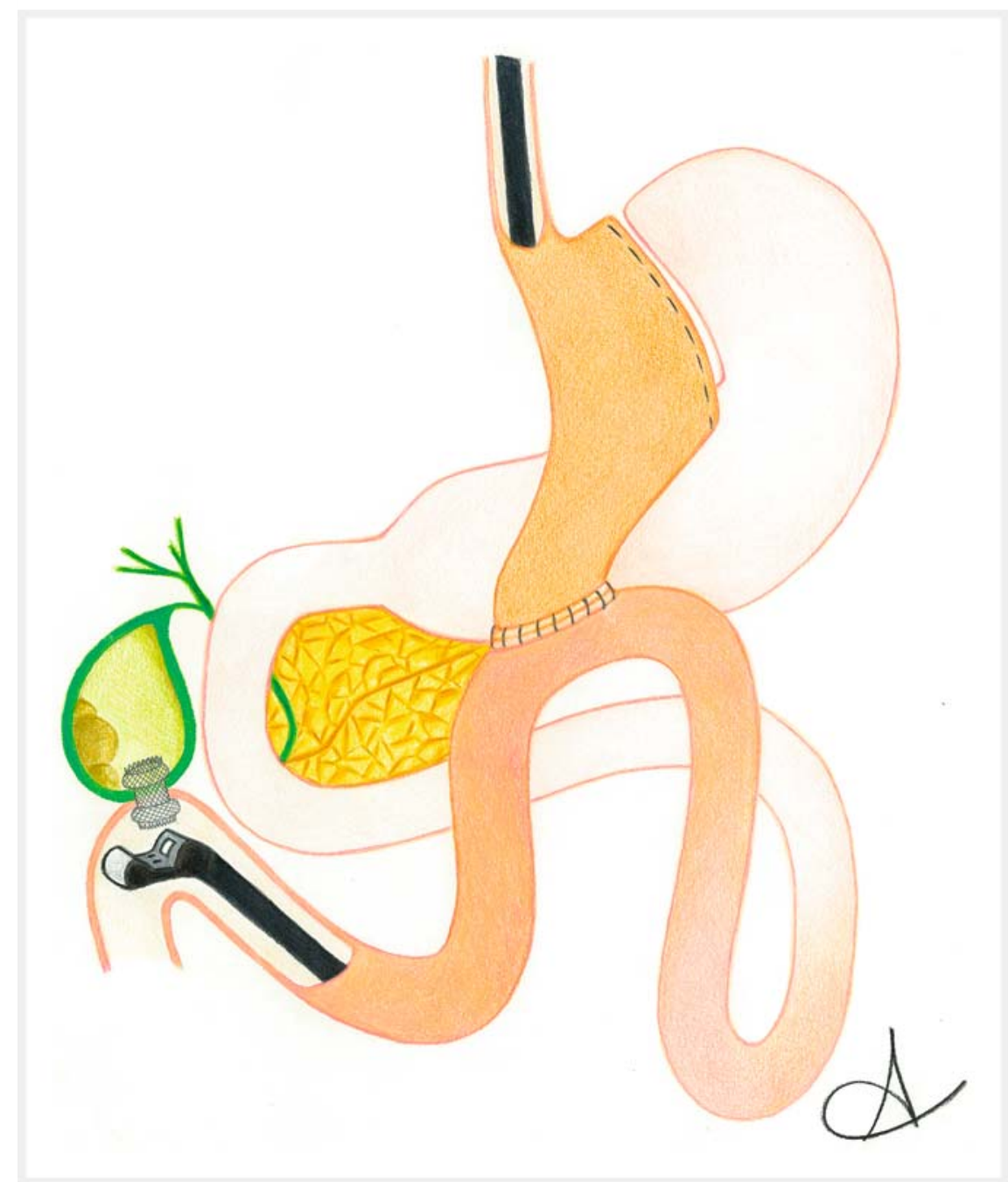

- Fig. 2 Graphical representation of transjejunal endoscopic ultrasound-guided gallbladder drainage in a patient with a mini-gastric bypass.

place draining purulent bile; however, the stent lumen was partially clogged by biliary debris. Under endoscopic guidance, a stone extraction balloon catheter was placed into the stent and the debris was removed. A 7-Fr nasogallbladder drainage tube was then placed through the stent (> Fig.4).

In the following days, the fever resolved and inflammatory markers returned to normal levels. The nasogallbladder drainage tube was removed and the patient was discharged home. At 3-month follow-up, the patient remained asymptomatic with improvement in general status, allowing surgery to proceed. The EC-LAMS was removed using a gastroscope and snare without complications, and an elective cholecystectomy was planned.

Endoscopy_UCTN_Code_TTT_1AS_2AD 


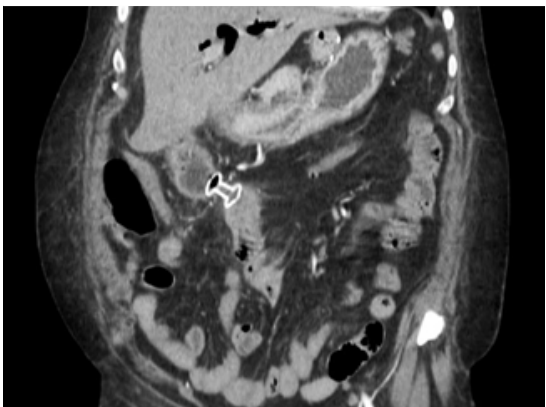

Fig. 3 Computed tomography demonstrating the correct positioning of the electrocautery-enhanced lumen-apposing metal stent between the jejunal efferent loop and the gallbladder lumen.

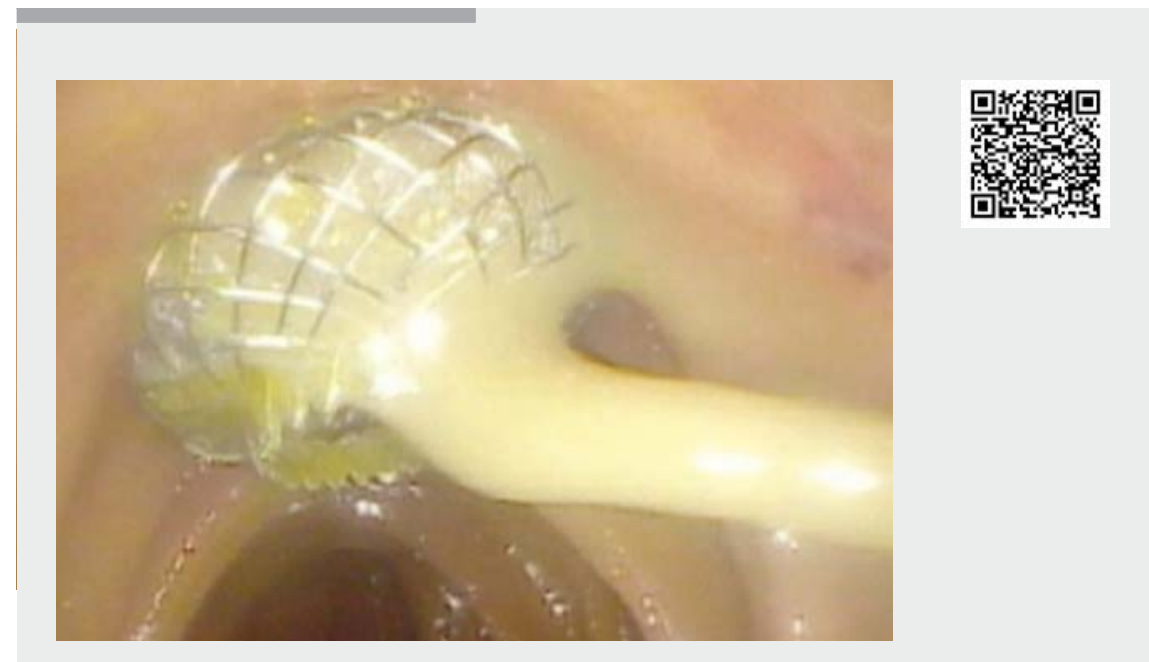

$\checkmark$ Video 1 Endoscopic ultrasound-guided gallbladder drainage by transjejunal placement of a lumen-apposing metal stent.

\section{Competing interests}

The authors declare that they have no conflict of interest.

The authors

Annalisa Cappello ${ }^{1}$, Alessia Santini ${ }^{2}$, Ivano Biviano ${ }^{2}$, Elena Gianni ${ }^{1}$, Natalia Simonetti ${ }^{1}$, Sandro Giannotti ${ }^{1}$, Raffaele Macchiarelli ${ }^{2}$

1 Gastroenterology Unit, A.O.U.S. Policlinico

S. Maria alle Scotte, Siena, Italy

2 Biliopancreatic Unit, A.O.U.S. Policlinico

S. Maria alle Scotte, Siena, Italy

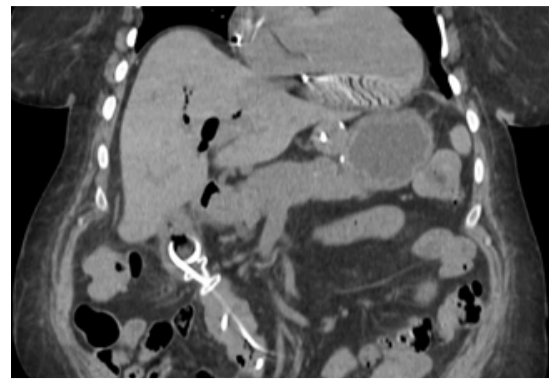

- Fig. 4 Computed tomography documenting nasogallbladder drainage tube placed through the metal stent into the gallbladder lumen.

\section{Annalisa Cappello, MD}

Gastroenterology Unit, A.O.U.S. Policlinico S. Maria alle Scotte, Viale Bracci, 53100, Siena, Italy annalisacappello@yahoo.it

\section{References}

[1] Krishnamoorthi R, Irani S. Endoscopic ultrasonography-guided gallbladder drainage using lumen-apposing metal stents. Tech Innov Gastrointest Endosc 2020; 22: 19-23

[2] Yokoe M, Hata J, Tadahiro T et al. Tokyo Guidelines 2018: diagnostic criteria and severity grading of acute cholecystitis (with videos). J Hepatobiliary Pancreat Sci 2018; 25: 41-54

[3] Kohji O, Kenji S, Tadahiro T et al. Tokyo Guidelines 2018: flowchart for the management of acute cholecystitis. J Hepatobiliary Pancreat Sci 2018; 25: 55-72

\section{Bibliography}

Endoscopy 2021; 53: E81-E82

DOI 10.1055/a-1196-1201

ISSN 0013-726X

published online 26.6.2020

(c) 2020. Thieme. All rights reserved.

Georg Thieme Verlag KG, Rüdigerstraße 14, 70469 Stuttgart, Germany

\section{ENDOSCOPY E-VIDEOS \\ https://eref.thieme.de/e-videos}

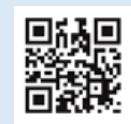

Endoscopy E-Videos is a free access online section, reporting on interesting cases and new techniques in gastroenterological endoscopy. All papers include a high quality video and all contributions are freely accessible online.

This section has its own submission website at

https://mc.manuscriptcentral.com/e-videos 